THE INTERNATIONAL

REVIEW OF RESEARCH IN

OPEN AND DISTANCE LEARNING

\title{
Facebook Groups as LMS: A Case Study
}
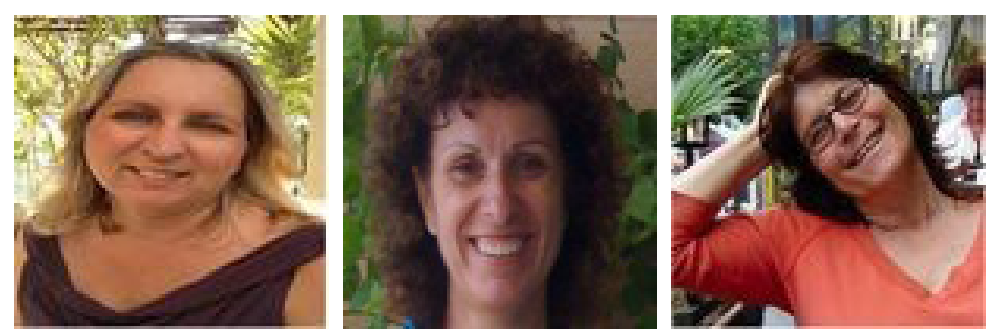

Hagit Meishar-Tal', Gila Kurtz ${ }^{2}$, and Efrat Pieterse ${ }^{1}$ ${ }^{1}$ The Open University of Israel, ${ }^{2}$ The College for Academic Studies, Or Yehuda, Israel

\section{Abstract}

This paper describes a pilot study in using Facebook as an alternative to a learning management system (LMS). The paper reviews the current research on the use of Facebook in academia and analyzes the differences between a Facebook group and a regular LMS. The paper reports on a precedent-setting attempt to use a Facebook group as a course Web site, serving as a platform for delivering content and maintaining interactions among the students and between the students and the instructor. The paper presents findings from the students' self-assessments and reflections on their experience. The students expressed satisfaction with learning in Facebook and willingness to continue using these groups in future courses.

Keywords: Facebook; LMS; learning management system; collaborative learning; elearning; social media

\section{Introduction}

The use of learning management systems (LMS), such as Blackboard and Moodle, has become common in many universities and colleges all over the world. The role of the LMS is to serve as a platform for course sites and to fulfill three goals: 1) to provide students with digital learning materials, such as articles, presentations, summaries of lessons, and arrange them in a way that reflects the course plan; 2) to employ interactivelearning activities with students in theforums, wikis, and other collaborative tools; and 3) to manage the course and the learners, maintaining tests, evaluating the students' learning and achievements, and giving grades online. In 2010, Facebook made it possible to create closed groups that allow asynchronous and synchronous interactions between members. This also allows sharing of information, such as links to Web sites, text documents, pictures, and so on. The Facebook group contains at 
least two of the three components of learning management systems, the digital content component and the interaction component, and thus raises the possibility that Facebook could turn into a learning environment and serve as an alternative learning management system. In this article we analyze the potential of Facebook to replace the traditional LMS. We would like to find out whether a Facebook group is an appropriate platform for delivering learning processes and how this environment differs from other LMSs.

\section{Literature Review}

\section{Learning Management Systems}

A learning management system (LMS), also called a virtual learning environment (VLE), is software that enables course sites to be created (Sclater, 2008). These systems are purchased and maintained by the educational institution to provide students with a space for online learning. An LMS is usually a password-protected system which enables the educational institution to open multiple course environments with relative ease. The course environment is typically managed by the instructor (educator). The educator has the authorization to upload content to the site, organize the materials in the educational continuum that reflects the course, open discussion groups, and manage the information uploaded to the newsgroups, including the option to delete inappropriate content from it. The educator can view reports of the users' activities and receive students' work in order to assess it. In many LMSs the system is linked to other administrative systems in the organization, such as the registration system, payments system, and so on. The students' permissions are usually more limited than those of the educator. Students registered for the course can view the content and download it. They can take part in interactive activities that take place in forums and in some cases may also contribute content to specific parts of the site, such as wiki environments or special collaborative repositories defined for this purpose by the course manager. Different learning management systems have different user interfaces and different features. However, they all share three key functions (Morgan, 2003; Coats, James, \& Baldwin, 2005).

1. Content management system: Allowing the creation or uploading of a variety of content items, such as texts, presentations, scanned articles, and audio-visual materials. The content management system also enables the material to be organized in a structure planned by the course administrator, creating folders for topics and content.

2. Tools for managing interactions: Different learning management systems allow the instructor to open different forums. Some systems allow the opening of asynchronous spaces for collaboration, such as wikis and blogs, and some can provide synchronous communication using chat and other online conferencing tools.

3. Tools for managing and assessing learners: Some systems provide administrative tools for recording tasks, grades, and feedback. They also provide user reports that support the instructor in measuring the level of the learners' participation and in assessing the students' achievements. 
An LMS should accomplish several goals for the learner. Academically, it should provide a space where learning can take place independently as the instructor is not present at the time of learning, and the students must cope with the content and the tasks themselves (Vrasidas, 2004). On the other hand, the LMS should also provide a social space aimed to create interaction between learners (Dillenbourg, Schneider, \& Synteta, 2002). The purpose of the interaction is to increase motivation for learning, creating mutual support among students and encouraging constructive learning.

Nevertheless, studies exploring the use of LMSs in higher education show that the use of these systems is usually limited. Their main use is for simplistic models of auto-evaluation using a multiple-choice questionnaire, and they do not incorporate elements of alternative assessment (Coats, James, \& Baldwin, 2005). Many professors who use course sites alongside face-to-face classes make only a basic use of them, uploading teaching materials and publishing one-way messaging to students (Nachmias \& Ram, 2009; Shamla \& Nachmias, 2007). These findings suggest that an LMS does not in itself produce new models of teaching and learning. Only a minority of instructors are using these environments in innovative ways.

Moreover, LMSs are very expensive systems. Even the so-called "free" open source systems require adaptation and ongoing maintenance by skilled technical staff. Another disadvantage of LMSs is the fact that in many institutions the course is deleted from the LMS server some time after the end of a course in order to save storage space. In some cases the learner loses the permission to enter the learning environment as the course ends; thus, access to the course materials is no longer possible. The control of the student over the LMS is limited.

The hierarchical structure of the LMS, as described above, has aroused much criticism among researchers. They argue that the organizing principle behind the LMS is actually the traditional centralized and hierarchical structure, discouraging the wide adoption of LMS's, and thus preventing innovativeand cutting edge pedagogy in these environments (Dron, 2006; Sclater, 2008).

If the Facebook group could meet the purposes of learning management systems, and if it could overcome some of the disadvantages indicated in the management and operation of learning using these systems, there is a reasonable possibility that a Facebook group could be a real alternative to an LMS.

\section{Main Differences Between a Facebook Group and a Conven- tional LMS}

A comparison of the characteristics of a Facebook group and the properties of an LMS reveals fundamental differences between the two.

1. Ownership: An LMS is managed and controlled by the educational institution, while Facebook groups belong neither to the organization nor to the students. They are allegedly "neutral," belonging to Facebook. This has its pros and cons. On the one hand, 
depending on Facebook is risky in terms of content backup and privacy issues; on the other hand, the environment is free of charge and does not require any maintenance. Moreover, the fact that the course site is not under the ownership of the institution embodies a deep change in attitude towards ownership of knowledge. The knowledge and information uploaded to the course site is no longer exclusively related to the educational institution but is jointly owned by the learners and educators (Mott, 2010).

2. Login: Participating in LMS environments requires having a username and password, created by the educational institution that provides the platform. The username and password, in most cases, are exclusive to the institution and force the student to manage another account besides his day-to-day private account. As a Facebook user, joining a Facebook group does not require handling another account; the student uses the same username for leisure and learning. On the other hand, a Facebook profile is required in order to participate in a Facebook group. This may raise objections among learners who are not interested in having a Facebook account.

3. Creating and sharing content: An LMS provides powerful tools developed to create and store a vast variety of content, including presentations, videos, and more. A Facebook group is very limited in terms of its ability to upload content. At the time of the pilot study the system did not allow uploading of the word processor, spreadsheet, PPT, and PDF files which are usually used by students and instructors. To overcome this problem it was necessary to develop strategies for integrating content from other Internet platforms, such as Google Docs, with Facebook (Wang, 2011). During 2012 Facebook upgraded the groups interface and added the option of uploading files directly to the group space.

4. Content management: The management of content in an LMS is concentrated in the hands of the educator who has the permissions to create, publish, and delete content. The students, in most cases, are allowed to consume the content. In a Facebook group there is a close similarity between the permissions of students and educators. All users can create content, delete content, invite participants to join the group, and so on.

5. Organizing content: In an LMS the organization of content is up to the educator. Facebook organization of content is controlled neither by the users nor by the administrator but by the technology in a "dynamic organization" such that newer news feeds are always at the top of the list, as are comments to old feeds that push old feeds to the top. This is perhaps the main weakness of the Facebook groups. The dynamic organization of the environment makes orientation and retrieval of content difficult. On the other hand, this is also its main strength: The dynamic organization produces the engine that generates interaction and encourages active participation.

6. Relationship between content and interaction: One striking difference between the LMS and the Facebook group is the relations between the content management elements and the interaction elements. In the conventional LMS there is a separation between the two. The instructor can create a content item (e.g., presentation) or an 
interactive item (e.g., forum), but each item stands on its own. In Facebook groups, however, interactions and content are all created through the status bar, so each item, whether it is content or interaction, is automatically added to the wall with the added option of commenting on it or adding "like" to the item. This special design makes interaction inherent in the content. Using Facebook only as a repository is therefore almost impossible with this structure.

7. Synchronous interaction: Most traditional learning management systems allow limited synchronous interaction between learners. However for Facebook groups, synchronous interaction is the main mode of communication between users. As stated above, the environment is provided with a special indicator so that whoever visits the Facebook group and is active at a given moment appears as active on his fellow group members' screens. Group members can communicate synchronously in a private channel and also in the group channel. The possibility of synchronous dialogue enhances the interactivity between the users of Facebook groups, making it a social space rather than just a learning space sand indirectly supporting learning in an informal way.

8. Assessment tools: The LMS provides the instructor with many different tools to assess learning, ranging from multiple choice questionnaires through activity reports about students' submissions, tasks, and mark books. A Facebook group does not have most of these capacities. The only tool built into the Facebook group which could be used for assessment is the internal search tool. By typing a name in the search bar, the instructor can create a user activity report. The report separates between the activity of initiating a new status and comments on existing statuses. The report does not include "like" responses. The combined use of a Facebook group with Google Docs may extend, to some degree, the possibilities of submitting written tasks and of using multiple choice questionnaires (forms).

Despite the significant differences between the Facebook group and the traditional LMS, there seems to be grounds for using the Facebook group as an alternative to an LMS. A Facebook group has several distinct advantages over a conventional LMS, as well as some major disadvantages for learners and educators. Using a Facebook group as an LMS challenges the learners and the educators to provide original and creative solutions for learning in this environment. Later in this article we describe a case study where a Facebook group was used as an alternative to an LMS in a graduate course in education at The College for Academic Studies, Or Yehuda, Israel.

\section{Facebook and its Use in Academia}

Social network sites like Facebook have gained tremendous traction recently as a popular online hangout spaces for both youth and adults (Boyd, 2010). Facebook is the most popular social networking site in Israel and all over the world. According to the CheckFacebook site (see www.checkFacebook.com), there were 3.48812 million Israeli Facebook members in August 2011. According to a comScore survey, the penetration rate in Israel among Internet users aged $15^{+}$was $89.8 \%$, placing Israel in second place after the Philippines. Israel leads in the duration of use of Facebook, with users staying on the Facebook site 
for about 10.5 hours per month (see www.comscore.com). Like any new web environment, Facebook groups were not developed for learning and teaching purposes. Nevertheless after a while Facebook began to be used in the academic context. The first studies in using Facebook in academia were conducted in order to examine the students' use of social networks in general (Pempek, 2009). More focused studies have examined the students' use of social networks for academic studies. These studies found that social networks are one of the tools used by new students to adjust and meet other students before and during school (Madge et al., 2009). A British study examined the content shared through Facebook by students in college. The research revealed that only $4 \%$ of the content posted by students contained material related to their studies. The content related to experiences out of university, the exchange of practical information about the course curriculum, and the sharing of academic information. Facebook was also used as a channel for expressing difficulties in learning so as to gain moral support from friends and for sharing humorous aspects related to the learning experience (Selwyn, 2007).

Other studies have explored the possibility of instructor-student interaction online. One of the problems identified in this context related to the willingness of instructors to be "friends" of their students, thus exposing themselves to the students, and vice versa. The merging of the social with the educational environment is perceived as a violation of privacy in many cases (Abel, 2005; Hewitt \& Forte, 2006; Mendez et al., 2009). Research conducted by Mazer et al. (2007) dealt with the effect of the exposure of the personal lives of instructors to their students through Facebook. This study shows that in most cases the increased exposure of the instructor through Facebook helped the students to perceive the instructor as being more human and trustworthy. At the same time, the researchers emphasize that overexposure may be a sensitive matter. Many instructors are not interested in this exposure and prefer not to share their personal lives with the students. Many students too are not interested in this exposure; they prefer a separation between learning space and social space. In light of these findings, it seems that Facebook is not a suitable environment for formal learning activities that require instructor-student interaction (Madge et al., 2009).

With the advent of "groups" on Facebook, which do not require members of the group to be "friends," it became possible to create a "study group" in which students and instructors participate without being "friends." Under these conditions, the possibility of using the Facebook group as an alternative to an LMS becomes relevant. A Facebook group can be created by any Facebook user. The creator of the group can invite other Facebook users to register for the group by forwarding a request to join it. The group administrator (creator) can choose to close the group or to leave it open. In the case of a closed learning group, the information published in the group does not appear on the user's "wall" as do all other activities on Facebook, but is published only among group members on the group wall.

\section{The Facebook Group Interface}

The center of the Facebook group is the wall. Members of the group can share content, statuses (plain text messages), links to Web sites, pictures, and videos on the wall.

Each item uploaded to the wall can get responses, either by indicating "like" or by 
writing a more detailed comment. The organization of the information on Facebook is dynamic as new items appear at the top of the list, and old items with new responses are also pushed to the top of the list. The wall is thus always reorganized in such a way that the newest items and the newest comments are always at the top. The Facebook group wall also allows the creation of documents (docs). The docs are part of the items posted on the wall but can also be accessible from a special box on the group page. The documents generator of Facebook is a very simple editor, providing only minimal design of text. Another tool of the Facebook group is the "events" generator. Events are items that are time-dependent and allow the members of the group to "attend" or "not attend."

The profile pictures of all members of the Facebook group appear on the group page. There is a special sign to indicate those currently on Facebook. Group members can use the oneto-one instant messaging system to talk with each other, as well as group conferencing to chat with the entire group. The group also provides an internal search engine that supports information retrieval from the environment.

An attempt to use a Facebook group as a substitute for an LMS is described in an article by Wang etal.(2011). The authors argue that the Facebookgroup has the potential to beused as an alternative to an LMS because it contains the pedagogical, social, and technological elements required from an LMS. It allows the sharing of materials and resources and it allows discussions to take place. However, the authors argue that the Facebook environment is still perceived to some extent as an unsafe environment that violates the privacy of the participants. Another study measured the extent of involvement of students in discussions on Facebook compared to a traditional course site. The findings indicated that the number of messages in the discussion that took place on the Facebook group was $400 \%$ higher compared to a parallel discussion on the WebCT forum. The authors explain the increase in the volume of activity in Facebook by the fact that "students were already accessing Facebook for personal use and checked in on the group when they accessed Facebook for other reasons" (Schroeder \& Greenbowe, 2009).

\section{Case Study in Using a Facebook Group as an Alternative to an LMS} The course "International Aspects of ICT in Education" was taught in the graduate program in education in the school of Education, The College for Academic Studies in Or Yehuda in the summer semester of 2011. The course is a face-to-face course, with class meetings once a week over 13 weeks. There were 50 students registered for the course, all of them computer literate. The students had opened a Facebook group for social goals before the course. This group was informal and registration was voluntary, not required.

The Facebook learning group was opened at the beginning of the course. The students were required to register for it as part of the course as the course tasks were published in the group and were part of the final grades in the course. 
Using the Facebook group included the following components.

1. Course presentations: The course presentations were published in the group after class. Publishing the presentations required integration between Facebook and Google Docs. In the first stage the instructor uploaded the presentations to Google Docs and defined them as "accessible to everybody with a link." The instructor then created a Facebook group, Doc, and added a link to the presentations. The reason for creating a Doc group and not just publishing a link on the wall was the desire to ease the accessibility to the content created by the instructor and differentiate it from other posts. Once the presentations were published, they were also accessible from the wall and everybody could respond to them and download them.

2. Performing tasks: The activity in the Facebook group consisted of five tasks, including searching, collecting information and sharing it with colleagues, peer assessment, online discussions, and quantitative and reflective self-assessment. The tasks also incorporated Google Docs. Students were asked to fill out forms prepared in Google Docs. After completing the forms, the database that was created as a joint task was published back on Facebook and analyzed by the students.

3. Questions and requests for the instructor: The Facebook group was also used as a means of communication between the students and the instructor. The students could choose either the personal channel (mail) of communication or the public channel (writing on the group wall). The students generally preferred to publish their questions on the wall.

\section{Methodology}

After completing the activities, the students performed a summative assessment task. In this task, the students were asked to reflect on their activities in the Facebook group and to report on the difficulties which had occurred during learning. The information was gathered into a Google Docs form for the researchers to analyze.

Content analysis of the responses from the reflections was carried out in two stages. Initially, recurring themes were identified by all three researchers and a list of the main themes was created based on agreement between the judges. In the second phase, one researcher coded all the statements. Review of encodings was by another researcher. The level of reliability between judges was over $85 \%$.

\section{Students' Assessment of the Facebook Group Activities}

Analysis shows that the students experienced the learning in Facebook as contributing in three regards: interaction with their colleagues, communication with the instructor, and correlation with their personal learning style. A fourth theme was also reported, expressing intensity and immediacy as a major experience at all three levels. 
Table 1

Main Themes $(N=43)$

\begin{tabular}{|l|l|r|}
\hline \multirow{4}{*}{ Level } & Theme & Frequency \\
\hline \multirow{4}{*}{$\begin{array}{l}\text { Interaction with } \\
\text { colleagues }\end{array}$} & Collaborative learning & $32 \%$ \\
\cline { 2 - 3 } the instructor & Mutual support & $23 \%$ \\
\cline { 2 - 3 } & Group consolidation & $20 \%$ \\
\cline { 2 - 3 } & Support in learning & $53 \%$ \\
\hline Personal learning & Initiative behavior & $16 \%$ \\
\cline { 2 - 3 } & Reactive behavior & $11 \%$ \\
\cline { 2 - 3 } & & $\mathbf{2 5 \%}$ \\
\cline { 2 - 3 } & Self-expression & $13 \%$ \\
\cline { 2 - 3 } & Passive presence & $25 \%$ \\
\hline & & \\
\hline
\end{tabular}

\section{Interaction with colleagues.}

Of the 43 students who responded to the questionnaire ( $86 \%$ response rate), $32 \%$ highlighted collaborative learning as their main experience. An example can be found in the following statement:

The messages and responses have been the most enjoyable part of the conversation in the group. The issues were raised not by the instructor but by the students, who wished to respond and share. In some cases, a deep discussion was developed and encouraged many friends to make interesting comments (like the discussion opened by Arthur on whether to permit young children to go into Facebook ). I really enjoyed taking part in these conversations. In my opinion, this is the real contribution of the Facebook environment for learning in this course.

The importance of the Facebook group as a joint space for class consolidation was emphasized by $23 \%$ of the students, as evidenced by the following comment: "We have been exposed to a variety of opinions and learning materials. An instant connection was created between everyone. I feel that the environment contributed to the consolidation of the group." Twenty percent of the students referred to the advantage of having a place in which the 
students could mutually assist each other either technically or academically; for example, "In addition, I took advantage of accessibility to all the students for giving and receiving mutual aid regarding issues taught in the course.

\section{Interaction with the instructor.}

The Facebook group activities were seen by $53 \%$ of the students as part of the course requirements, and their work was aimed at fulfilling the tasks.

The advantage of the environment for gaining assistance and clarification in the learning process was emphasized by $16 \%$ of the students. It seems that there is a correlation between these themes and the overall activity level of students. Students whose activity was minimal are the ones who only work to fulfill their obligations, as expressed in the following quotation: "I would summarize my activity on Facebook as doing just what I had to and nothing more."

On the other hand, the more active students emphasized the advantage of having an interaction with the instructor beyond the particular tasks, as evidenced by the following comment:

The environment has allowed a direct link between the students and the instructor. She became an advisor, she gave us the tools and exposed us to information sources and learning tools, and gave us immediate feedback. This is meaningful learning for me.

\section{Personal learning.}

The students experienced the effects of the Facebook environment on their learning in different ways related to their personal learning style and their characteristics. Eleven percent of the students described their activities as initiating and proactive, while $25 \%$ described them as reactive. An example of a reactive style is shown in the following statement: "I didn't initiate new statuses and this is my weakness in this type of learning. But every time I had to respond or perform a task, I followed the instructions in their entirety." The proactive style is shown in the following quote: "There were messages I initiated on my own, because of an issue arising from the course material that I wanted to share with my friends and stimulate discussion."

Another distinction reflected in the findings is between students who experienced this space as enhancing self-expression (18\%) and students who described a more passive way of participation (13\%), meaning reading and following-up or pressing "like." For the passive student, using "like" was a way of allowing them effectively to show an active presence in the environment without having to express themselves in more detail. This is expressed in the following quotation: 
My reaction to the members of the group was "like," which for me is also a kind of a response that supports the teammates. I liked it (literally) when friends did it to me, and I felt that what I wrote to them is significant for them and for the discussion.

\section{Intensity.}

Twenty-five percent of the students repeatedly emphasized that the online learning experience was intense, immediate, and fast. One of the students even defined the experience as "catchy:" “There is something 'catchy' in the responses and therefore we see more comments." An example of the experience of immediacy and intensity at all levels can be found here:

We created an instant connection between us all. I feel that the environment contributed to the consolidation of the group, direct contact with the participants and of course, a place to "hear" all of them on any subject that came up. The ability to speak up immediately was very convenient and suited me very much. I used it in many cases. Rapid response of all the classmates gave a sense of a real "conversation" and made me continue responding and expressing agreement or disagreement, with the need to justify why.

\section{Students' Difficulties During the Course}

The second question that the students answered related to the difficulties they faced during the course. Of the 43 students, $34 \%$ reported that they had no difficulties at all. The difficulties commonly faced by the students were 1) difficulty in locating old items and orientation problems (39\%); 2) workload (27\%); 3) uncomfortable blurring of the boundaries between social space and student space (4\%); and 4) difficulty in expressing oneself in writing and in participating (4\%).

\section{Difficulty in locating items and in orientation.}

The dynamic structure of Facebook content was a serious problem for students who found it difficult to locate important information they wanted to retrieve during learning. The solution found is that most important items (presentations, assignments, etc.) were created in the DOCs section of the existing Facebook group. The DOCs are easier to access because there is a special place for them on the sidebar. It seems that this solution eased orientation, as evidenced by the following quotation: "The difficulty in the beginning was to find the materials and the tasks, until they were transferred to the sidebar and concentrated there and that solved the problem." The students also learned to use the existing internal search provided in the group as another retrieval tool. 


\section{Workload.}

The intensity of learning was experienced by some students as a heavy burden, as expressed in the following comment: "The main difficulty involved in the Facebook group was the need to stay informed at all times. Messages frequently changed and to understand the mindset I had to enter the group every day. That required a commitment that I haven't experienced in most other courses."

\section{Uncomfortable blurring of the boundaries between the social and the academic arenas.}

Although the group was closed and did not require exposure of the personal profile, some students still felt some discomfort in the fact that Facebook is considered a social environment yet also serves as a learning environment, as shown in the following statement: "Facebook is a place where I talk with and update my closest friends and relatives. I go there to get away from the routine (cleaning up, cooking and studying), and with the existence of the group it was hard to make the separation."

\section{Difficulty in expressing oneself in writing.}

We mentioned above the relationship between the learning style of the students and how they experienced the learning environment. We have seen that there is a substantial difference between initiating and reacting, proactive and passive. It seems that for some students the reason for passivity is their difficulty in expressing themselves in writing and in public, as expressed, for example, in the following quote:

There were many cases where I wrote responses but didn't publish them. The idea of the exposure of my words, kept there forever in black and white, deterred me for some reason (maybe there's a psychological reason). Anyway, I'm disappointed that my participation was so low.

In conclusion, the students were asked to indicate, on a scale of $1-5$, the extent to which the Facebook group contributed to their learning on the course. The average score was 4.1. For the question "Would you recommend using this form of Facebook group on other academic courses?" $86 \%$ of the students answered 'yes' and $14 \%$ answered 'no.'

\section{Discussion and Conclusions}

The student's reflection on their learning with a Facebook group indicates that learning in this environment is perceived as very intensive and collaborative in nature. The students emphasized the importance of the environment in evoking mutual support and social consolidation, factors that support collaborative learning processes. Unlike traditional LMSs which are mainly used at the trivial content-based level, the learning Facebook group is perceived as a dynamic learning environment. 
An interesting finding emerged from the research which is the student's perception of the Facebook group as a stimulator of participation, both proactive or reactive. Students felt that Facebook encouraged them to express themselves. Even passive students had the ability to express their presence on the Facebook group by indicating "like" on chosen posts.

These unique characteristics of the Facebook group brings us to the conclusion that the Facebook group is not just an alternative to LMS (Wang, 2011) but have some major advantages over traditional LMSs in promoting collaborative and active learning.

The advantages of the Facebook group are also its disadvantages. The intensive dynamic of the group activity is perceived by some students as a load, weighing on students' daily routine. This dynamic comes largely at the expense of organization and orientation in the learning space. Intelligent use of existing tools and groups for information organization (docs and search tools) significantly improves the problem of orientation.

\section{Summary}

The case study described above demonstrates that design and operation of a learning activity within a Facebook group produces a very intensive and collaborative learning process. The reason for that must lie in the unique dynamic structure and special features that differentiate it from other learning management systems. The group is designed in a way that encourages participation and interaction on every single post uploaded to the group; therefore, it can be leveraged to carry out learning processes that require interactivity between learners and between learners and the instructor. The Facebook group is not just "another discussion group" but a unique environment that can serve as an interesting alternative to elaborate collaborative learning processes.

Nevertheless, we must remember that the environment itself is not solely responsible for the creation of learning dynamics (Dillenbourg, Schneider, \& Synteta, 2002). The role of the instructor in designing the tasks, the speed and quality of her responses during the tasks, the motivation of learners and the fact that the Facebook activity was a large part of the requirements of the course and part of the final grade all contributed to the success of the activity and the dynamics that were developed. Continuing research that compares this environment in other study groups, and with different models of teaching, could contribute to the understanding of the influence of Facebook groups as a learning environment. 


\section{References}

Abel, M. (2005). Find me on Facebook ... as long as you are not a faculty member or administrator. Resource for College Transitions, 3(3), 1-12.

Boyd, D. (2010). Social network sites as networked publics: Affordances, dynamics, and implications. In P. A. Zizi (Ed.), Networked self: Identity, community, and culture on social network sites (pp. 39-58). Retrieved from http://www.danah.org/papers/2010/SNSasNetworkedPublics.pdf

Cheung, C. M. K., Chiu, P., \& Lee, M. K. O. (2011). Online social networks: Why do students use Facebook? Computers in Human Behavior, 27(4), 1337-1343.

Coats, H.J.R., \& Baldwin, G. (2005) A critical examination of the effects of learning management systems on university teaching and learning. Tertiary Education and Management, 11(1), 19-36.

Dillenbourg, P., Schneider, D., \& Synteta, P. (2002). Virtual learning environments. In A. Dimitracopoulou (Ed.), Proceedings of the 3rd Hellenic conference on information and communication technologies in education (pp. 3-18). Greece: Kastaniotis Editions.

Dron, J. (2006). Any color you like, as long as it's Blackboard. Paper presented at the World Conference on E-Learning in Corporate, Government, Healthcare and Higher Education, Honolulu, Hawaii, USA.

Furkush-Baruch, A., \& Heshkovitz, A. (2011). The use of social networks by higher education institutes in Israel. Y. Eshet-Alkalai, A. Caspi, S. Eden, N. Geri, Y. Yair (Eds.) Proceedings of the Chais Conference on Instructional Technologies Research 2011: Learning in the Technological Era. Raanana: The Open University of Israel.

Grosseck, G., Bran R., \& Tiru, L. (2011). Dear instructor, what should I write on my wall? A case study on academic uses of Facebook. Procedia - Social and Behavioral Sciences, $15,1425-1430$.

Hew, K. (2011). Students' and instructors' use of Facebook. Computers in $\mathrm{Hu}$ man Behavior, 27, 662-676. Retrieved from http://portal.acm.org/citation. $\mathrm{cfm}$ ?id=1937203.1937626

Madge, M., Meek, J., Wellens, J., \& Hooley , T. (2009). Facebook, social integration and informal learning at university: 'It is more for socialising and talking to friends about work than for actually doing work'. Learning, Media and Technology, 34(2), 141-155.

Mazer, J.P., Murphy, R.E., \& Simonds, C.J. (2009). The effects of instructor self-disclosure via Facebook on instructor credibility. Learning, Media and Technology, 34(2), 175-183. 
Mendez, J. P., Curry, J., Mwavita, M., Kennedy, K., Weinland, K., \& Bainbridge, K. (2009). To friend or not to friend: Academic interaction on Facebook. International Journal of Instructional Technology \& Distance Learning, September.

Morgan, G. (2003). Faculty use of course management systems. Retrieved from http:// www.educause.edu/ir/library/pdf/erso302/rs/ers0302w.pdf.

Mott, J. (2010) Envisioning the post-LMS era: The open learning network. EDUCAUSE Quarterly Magazine, 33, 1.

Nachmias, R., \& Ram, J. (2009). Research insights from a decade of campus-wide implementation of web-supported academic instruction at Tel Aviv University. The International Review of Research in Open and Distance Learning, 1O(2), 1-15.

Pempek, T. A., Yermolayeva, Y. A., \& Calvert S. L. (2009). College students' social networking experiences on Facebook. Journal of Applied Developmental Psychology, 30, 227238. Retrieved from http://www.educause.edu/EDUCAUSE+Quarterly/EDUCAUSEQuarterlyMagazineVolum/EnvisioningthePostLMSEraTheOpe/199389

Roblyer, M. D., McDaniel, M., Webb, M., Herman, J., \& Witty, J. V. (2010). Findings on Facebook in higher education: A comparison of college faculty and student uses and perceptions of social networking sites. Internet and Higher Education, 13(3), 134-140.

Schroeder, J., \& Greenbowe, T.J. (2009). The chemistry of Facebook: Using social networking to create an online community for the organic chemistry laboratory. Innovate: Journal of Online Education, 5(4). Retrieved from http://www.innovateonline. info/print.php?view $=$ pdf\&id $=625$

Sclater, N. (2008). Web 2.0, personal learning environments, and the future of learning management systems. EDUCAUSE Research Bulletin, 13. Boulder, CO: EDUCAUSE Center for Applied research.

Selwyn (2007). Screw Blackboard... do it on Facebook!': An investigation of students' educational use of Facebook. Paper presented to the 'Poke 1.0 - Facebook social research symposium', University of London.

Selwyn, N. (2009). Faceworking: Exploring students' education-related use of Facebook. Learning, Media and Technology, 34(2), 157-174.

Shemla, A., \& Nachmias, R. (2007). Current state of web-supported courses at Tel-Aviv University. International Journal of E-Learning, 6(2), 235-246.

Vrasidas, C. (2004). Issues of pedagogy and design in e-learning systems. Communications of ACM. Retrieved from http://portal.acm.org.ezproxy.massey.ac.nz/citation.cfm ?id=968086\&coll $=$ portal $\& \mathrm{dl}=\mathrm{ACM} \& \mathrm{CFID}=32263271 \& \mathrm{CFTOKEN}=96032385$ 
Vovides, Y., Sanchez-Alonso, S., Mitropoulou, V., \& Nickmans, G. ( 2007). The use of elearning course management systems to support learning strategies and to improve self-regulated learning. Educational Research Review, 2(1), 64-74.

Wang, Q., Woo, H. L., Quek, C. L., Yang, Y., \& Liu, M. (2011). Using the Facebook group as learning management system: An exploratory study. British Journal of Educational Technology. doi: 10.1111/j.1467-8535.2011.01195.x

\section{Athabasca University $\mathbf{I}$}

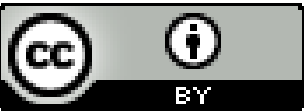

